\title{
Apoptosis, ANUP, Chromogranin A, PGP 9.5, Endothelins and VEGF in Acquired Heart Diseases: Review of Literature
}

\author{
Edite Kulmane*, Mara Pilmane**, Romans Lacis* \\ *Department of Cardiac Surgery, Pauls Stradins Clinical University Hospital, Latvia \\ **Institute of Anatomy and Anthropology, Riga Stradins University, Latvia
}

\section{SUMMARY}

According to the Centre for Disease Prevention and Control of Latvia data, in 201416076 latvians died from cardiovascular diseases and it is $57,03 \%$ of all deaths. Changes in myocardium of the diseased hearts are complex and pathogenesis is still not fully clear. Morphopathogenesis of cardiovascular diseases are complex molecular cell changes which include apoptosis, homeostasis regulating factors, and innervation and ischemia markers.

In this article we wanted to provide an overview about apoptosis, atrial natriuretic peptide, chromogranin A, neuropeptide-containing innervation, endothelins and vascular endothelial growth factor in pathomorphology of acquired heart diseases and their clinical implications.

Key words: apoptosis, ANUP, chromogranin A, PGP 9.5, endothelins, VEGF, heart

\section{INTRODUCTION}

More than 4 million Europeans die of cardiovascular diseases every year despite recent decreases in mortality rates in many countries including Latvia where in 2012 10 year change in mortality rate from cardiovascular diseases was $-19 \%$ for males and $-24 \%$ for females (65). Notwithstanding the fact, according to the Centre for Disease Prevention and Control of Latvia data, in 2014 16,076 thousands latvians died from cardiovascular diseases and it was $57,03 \%$ of all deaths (90).

Changes in myocardium of the diseased hearts are complex and pathogenesis is still not fully clear. Morphopathogenesis of cardiovascular diseases is complex molecular cell changes which include apoptosis, homeostasis regulating factors, and innervation and ischemia markers. Understanding the pathomorphology and its clinical implications of the cardiovascular diseases are important for every physician including cardiac surgeons, because the choice of treatment, surgical timing, pre and postoperative therapy depends on pathogenesis of the disease.

Programmed cell death (apoptosis) is a regulated mode of cell death in multicellular organisms (42). Apoptosis of cardiac muscle cells has been identified as an essential process in the pathogenesis and progression of heart failure which is a complication of other heart diseases (27).

Atrial natriuretic peptide (ANUP) is a cardiac hormone secreted mainly from atria in response to acute or chronic atrial stretch and is involved in fluid, electrolyte and vascular homeostasis (95).

Chromogranin A (ChgA) is a glycoprotein that is stored and released in the extracellular environment together with neurotransmitters and hormones in the nervous, endocrine and diffuse neuroendocrine systems (36).
ChgA measurement has gained interest in cardiovascular disease, because increased plasma concentrations are associated with risk of clinical deterioration and death with acute coronary syndromes or chronic heart failure (37).

Protein gene product 9.5 (PGP 9.5) is a cytoplasmic neuron and neuroendocrine cell-specific protein used as general marker to visualize diffuse neuropeptidecontaining innervation $(74,97)$. PGP 9.5 has been proposed as reliable marker for visualisation of the cardiovascular system innervation (5).

Endothelin 1 (ET-1) is a potent vasoconstrictor and pro-inflammatory peptide (9). Endocardial endothelial cells and intramyocardial capillary endothelial cells are major source of ET-1 in the normal heart and cardiomyocytes are its primary target (67). Endothelins play an important role in cardiac and vascular pathology associated with heart failure (109).

Vascular endothelial growth factor (VEGF) is glycoprotein which is produced by a variety of adult tissues and vascular and inflammatory cells and it controlls vascular growth and function, vascular homeostasis, permeability, and vasodilatation $(25,47)$.

\section{Apoptosis}

Programmed cell death (apoptosis) is a regulated mode of cell death in multicellular organisms (42). Apoptosis plays a key role in maintenance of steady state in continously renewing tissues under both physiological and pathological conditions $(33,49)$. It is genetically driven and is characterized by chromatin condensation, nuclear shrinkage and eventual loss of nuclear membrane, membrane blebbing that produces apoptotic bodies containing cellular organelles and chromatin, DNA degradation into distinct nucleosomal units and 
energy and protein synthesis requirement (41). The controlled degradation of nuclear DNA is a hallmark of apoptosis (41).

Programmed cell death in heart can be induced by several stimuli, such as hypoxia, reperfusion injury, tumor necrosis factor alpha, aldosterone, sodium nitroprusside, mechanical stretching of ventricular cardiomyocytes $(12,39,50,54,78)$. Chlolesterol accumulation in macrophages leads to apoptosis and favors the formation of the necrotic core in complex atherosclerotic plaques (34). Cardiomyocyte apoptosis can be reduced by beta-adrenoreceptor blockers and inhibition of angiotensin converting enzyme $(45,48)$.

Apoptosis is not detected in normal adult human heart (101).

Apoptotic cell death is a component of myocardial infarction in acute myocardial infarction patients (77). Apoptosis is the first and predominant form of myocyte cell death in recently infarcted human myocardium before the ischemic myocyte cell death with typical coagulative necrosis (101). Acute myocardial infarction in humans is characterized also by activation of programmed cell death in the surviving portion of the left ventricular wall (69). Apoptosis affects 5.1 - 12\% of the myocyte population of the region bordering on the infarct $(69,83)$. Inflammatory cells that invade the infarct also undergo apoptosis (77). The higher rates of cardiomyocyte apoptosis are associated with more severe complications after myocardial infarction earlyer clinical manifestation of heart failure, left ventricular systolic and diastolic dysfunction, ventricular dilatation and death $(2,13,88)$. Apoptosis certainly is important in chronic ischemic conditions such as hibernating myocardium (84). Experimentally, apoptosis is particularly prominent during the transition from chronically stunned to hibernating myocardium, at which time there is a loss of approximetaly $30 \%$ of the regional myocytes (14).

Apoptosis of cardiac muscle cells has been identified as an essential process in the pathogenesis and progression to heart failure (27). Apoptotic index in end stage dilated cardiomyopathy ranges from 5.0 - 35.5 (64). And predominantly it is observed in subendocardium or subepicardium (64).

\section{Atrial Natriuretic Peptide}

Atrial natriuretic peptide (ANUP) is a cardiac hormone secreted mainly from atria and is involved in fluid, electrolyte and vascular homeostasis - the maintenance of arterial blood pressure and intravascular volume (51, 95). ANUP is produced primarily by atrial cardiomyocyte and also in little amount by ventricular tissue in normal and failing (with either systolic or diastolic dysfunction) hearts and in hypertrophied ventricles $(10,11,15,76)$. For the first time ANUP was described by Bold et al. in 1980, when they observed decrease in blood pressure and greatly increased fractional excretion of sodium and chloride during the infusion of atrial extract in rats (10). Human ANUP precursor peptide gene reside on chromosome 1p36.2 and it's mRNA encodes a high molecular wight precursor peptide proANUP which is proteolytically cleaved by corin, a cardiac serin protease, into the biologically active ANUP $(15,76)$.

The natriuretic peptide family comprises five principal peptides: atrial natriuretic peptide (ANUP), brain natriuretic peptide (BNP), C-type natriuretic peptide, urodilatin and dendroaspis natriuretic peptide (15). B-type natriuretic peptide is a cardiac neurohormone specifically secreted from the ventricles in response to volume expansion and pressure overload (57). C-type natriuretic peptide has more widespread distrubution, mainly in human vascular endothelial cells, lungs, kidneys, CNS and reproductive organs $(15,68)$. It is potent endothelium-independent vasodilator, including coronary arteries $(15,19)$. Urodilatin is synthesized in the kidney distal tubules and interacts in a paracrine function with the tubular cells, and is mainly responsible for sodium-water homeostasis (31). Dendroaspis natriuretic peptide is one of the recent discovered ntriuretic peptides (85). It is present in healthy human plasma and is significantly increased in chronic heart failure patients (85). Similarly to ANUP and BNP, dendroaspis natriuretic peptide is widely distributed in the peripheral cytoplasm of atrial myocites and also in the perinuclear region (85).

ANUP is secreted from atrial granules into the circulation in response to acute or chronic atrial stretch to physiologically act as antihypertensive and antihypervolaemic factor (51). In adult human heart, chronic overload induces an increment in both ANUP and BNP, although it is grater in the latter, while a short term stimulus induces a greater increase in ANUP than in BNP $(15,100)$. ANUP is able to stimulate the production of cyclic guanosine monophosphate (GMP) (15). The physiologic actions include reducing both cardiac preload and afterload (decrement in peripheral vascular resistance) by their natriuretic, diuretic, and vasodilatory actions including selective renal vasodilation and inhibition of renin and aldosterone $(63,15,11)$. Reduction of cardiac pre-load is mediated by shifting of intravascular fluid into extravascular compartment, increment in venous capacitance and inducing of natriuresis (15).

ANUP synthesis is increased in various pathologic conditions, causing hemodynamic overload (95). The natriuretic peptides, including ANUP and BNP, are one of the most important counterregulatory systems that become activated in heart failure (58). Secretion of ANUP in the heart are increased in patients with congestive heart failure in relation to its severity (62). Plasma levels of ANUP are elevated also in patients with chronic kidney disease, mainly because of hypertension and hypervolemia and in hyperthyroid patients because of stimulating by thyroxin $(43,92)$. In the ventricles of heart with hypertrophic cardiomyopathy and hypertensive hypertophy, the expression of ANUP is augmented despite the absence of heart failure (94, 95). ANUP is found to be overexpressed in the myocytes surrounding myocardial lesions, such as myocardial infarction and myocarditis (95). In patients with cardiac 
amyloidosis biopsy specimens from right and left ventricles show slightly higher immunoreactivity for ANUP than in the control group (95). But endocardium, connective tissue, vasculature and amyloid fibers are not immunoreactive to ANUP in cardiac amyloidosis patients (95).

\section{Chromogranin A}

Chromogranin A (ChgA) is an acid, $\mathrm{Ca}^{2+}$ binding glycoprotein that is stored and released in the extracellular environment by exocytosis together with neurotransmitters and hormones in the nervous, endocrine and diffuse neuroendocrine systems $(36,73,16)$. ChgA is a member of the granin family, witch includes chromogranin B and secretogranin II (99). The gene encoding for ChgA is located in chromosome 14 (66). Originally chromogranin was discovered in the chromaffin granules of the adrenal medulla (16).

The serum concentration of ChgA is elevated in patients with various neuroendocrine tumours. Elevated levels are strongly correlated with tumour volume and the highest levels are recorded in subjects with metastatic neuroendocrine tumours (66). Increased levels of circulating ChgA also have been detected in postmenopausal women, heart failure, renal failure, hypertension, rheumatoid arthritis, sepsis, atrophic gastritis and in subjects treated with proton pump inhibitors $(24,66)$. This protein has long been known as a marker for neuroendocrine tumors, but it's role in cardiovascular disease has only recently been recognized (8).

Heart failure is a syndrome comprising cardiac dysfunction and neurohumoral activation (38). In 2007, Pieroni et al. for the first time demonstrated that human ventricular myocardium produces and releases Chg A, they showed that in the presence of dilated and hypertrophic cardiomyopathy, the peptide is also immunologically detectable on tissue sections $(73,99)$. In atrial myocytes it is co-stored with atrial natriuretic peptide and in the ventricle it co-localizes with brain natriuretic peptide $(99,104)$. ChgA measurement has gained interest in cardiovascular disease, because increased plasma concentrations are associated with risk of clinical deterioration and death in patients with acute coronary syndromes or chronic heart failure, even more - Jansson et al. demonstrated that circulating levels of ChgA provide prognostic information (long term mortality and heart failure hospitalization) independent of conventional risk markers in acute coronary syndromes $(37,99)$. ChgA levels have been found to reflect sympathetic activity, indicating that circulating ChgA levels may represent overall neuroendocrine activity. Increased activity in the sympathetic nervous system is a recognized risk factor for poor outcome in heart failure (82). ChgA is significantly increased in chronic heart failure patients due to tensile stretch during cardiac dilatation compared to healthy controls. After mechanical ventricular support ChgA decreases only in the heart, but not in the blood (6).
ChgA acts as a prohormone giving rise several biologically active peptides by proteolytic cleavage operated by several proteases and prohormone convertases in secretory cells such as vasostatin (a vasodilator), chromacin (an anti-microbial agent), pancreastatin (a dsyglycemic hormone), parastatin (blocks parathyroid hormone release) and catestatin (a potent inhibitor of catecholamine release from chromaffin cells and adrenergic neurons and an antimicrobial agent)(8, $24,52,99)$. The first of these peptides reported was pancreastatin, which inhibits glucose - stimulated insulin release from pancreatic beta cells and secretion of parathyroid hormone from the parathyroid gland (52).

Vasostatin is a peptide, derived from the N-terminal part of ChgA by serine protease $(24,66)$. It has been shown to inhibit vasoconstriction of human veins by antagonizing the endothelin mediated contraction of smooth muscle, it also can inhibit endothelial cell proliferation, migration and invasion induced by vascular endothelial growth factor $(22,52,66)$.

Catestatin is a catecholine release inhibitory peptide that can inhibit endothelin-1 induced positive inotropism and coronary constriction and can induce secretion of potent proangiogenic factor - basic fibroblast growth factor $(24,99)$. Catestatin is preventing hypertension by vasodilatation, decreasing peripheral and central symphathetic activity and reducing cardiac contractility (55). Mutations in the catestatin domain of the ChgA gene are associated with hypertension in humans (55). C-terminal ChgA- derived serpinin peptides are present in the rat heart and influence myocardial contractility (concentration dependent positive inotropic effect) and enhanced relaxation (positive lusitropy) in $\beta$-agonistlike manner, without affecting heart rate, providing innovative insight into the ChgA- elicited regulation of cardiac function (55). Serpenin peptides may contribute to cardiac homeostasis by counterbalancing the vasostatin 1 and catestatin induced cardiosupressive and antiadrenergic effects (55).

\section{Protein Gene Product 9.5}

Protein gene product 9.5 (PGP 9.5) is a cytoplasmic neuron and neuroendocrine cell-specific protein used as a general marker to visualize diffuse neuropeptidecontaining innervation $(74,97)$. PGP 9.5 was originally detected as a brain specific protein (97). PGP 9.5 has been proposed as reliable marker for visualisation of the cardiovascular system innervation (5).

In adult human heart there are abundant network of PGP 9.5 immunoreactive nerves in the walls of the atria, but in the ventricules relatively fewer $(21,59)$. Also in human newborns very numerous PGP 9.5 immunoreactive nerve fascicles and fibers are found in both - right and left atrial tissue and slightly less, but also numerous, in the walls of the ventricles (21). Within the atrial and ventricular myocardium PGP 9.5 pozitive nerve fibers are forming perivascular plexi along the walls of the major cardiac vessels and occasionally some separate nerve fibers are running in close relationship 
with myocardial cells $(21,40,81)$. Nerve fiber terminals are identified in the atrial endocardium, epicardium and coronary sinus (18).

PGP 9.5 immunoreactive varicose nerve fibers, nerve fascicles, and nerve trunks are observed throughout conduction system (sinus node, atrioventricular node, atrioventricular bundle and ventricular branches) of the human heart (23). The nerve density in conduction system is significantly higher than in the adjacent atrial or ventricular myocardium (23). And the most densely innervated region of conduction system is sinus node, where PGP 9.5 immunoreactive nerve fibers and fascicles are distributed between nodal cells in the fibrous tissue matrix (23). Abundant PGP 9.5 immunoreactive nerve fascicles and fibers are present in the sinus node of human newborns and the same as in adults - positively staining nerve fascicles and fibers are also seen among the cells of the atrioventricular node, bundle of His, and the branching bundle, the density of fibers being slightly less than in sinus node (22).

There are rich neworks of nerves immunoreactive to PGP 9.5 in cusps of atrioventricular - mitral and tricuspid valves and in chordae tendineae (5). The nerve fibres ramifies from the ventricles through the papillary muscles into the chordae tendineae and than passe up through the chordae to terminate in the valve cusp (5). The nerves of the terminal innervation network of the atrioventricular valves are part of a complex neural mechanism that is involved in the reflex control of the heart valves, chordae tendineae and papillary muscle during each cardiac cycle (5). In 1989. Kawano et al. described neuropeptide $\mathrm{Y}$ and calcitonin gene related peptide containing nerve fibre degeneration in a prolapsed mitral valve cusp (5).

Sympathetic overactivity, usually accompanied by reduced parasympathetic activity and heart rate variability, is increasingly recognized as a feature in the pathogenesis of a number of cardiovascular pathologies (40). Cardiac neuronal remodeling accompanies hypertension, post-myocardial infarct remodeling and heart failure (40). There is association between local nerve density and a clinical history of ventricular arrhythmia in patients with severe heart failure, and it is hypothesed that in some patients myocardial injury (myocardial infarction) results in nerve injury, followed by nerve sprouting and regional myocardial hyperinnervation (18). In patients with end stage heart failure due to severe coronary heart disease and miocardial infarctions there are found thicker and more numerous irregularly distributed nerve fibers in the scar tissue than in adjacent normal myocardium (103).

After cardiac transplantation human cardiac allografts remain functionally extrinsically denervated, but they still appear to contain viable intrinsic nerves (105). The relative number of PGP 9.5 immunostained nerves in transplanted hearts is less than in innervated (105). In patients after cardiac transplantation, reinnervation is associated with significantly improved exercise performace (18).

\section{Endothelin}

In 1988, a 21-amino-acid vasoconstricting factor termed endothelin was isolated from cultured porcine aortic endothelial cells $(46,106)$. Endothelins are family of peptides, which comprises endotheli-1 (ET1), endothelin-2 (ET-2) and endothelin-3 (ET-3) (4). ET-1 is primarily secreted by endothelial cells, but it can also be synthesized and released by a variety of cell types, such as cardiac myocytes, endocardial endothelial cells, intramyocardial capillary endothelial cells, kidney, central nervous system (CNS) and posterior pituitary $(58,67,75)$. Endocardial endothelial cells and intramyocardial capillary endothelial cells are major source of ET-1 in the normal heart and cardiomyocytes are its primary target (67). ET-2 is produced in endothelial cells, heart and kidney. ET-3 is expressed in endocrine, gastrointestinal and CNS, but not in endothelial cells $(4,58,75)$. Neonatal rat cardiac myocytes express preproET-1 mRNA and synthesize and secrete mature ET-1 (109). ET-1 is the predominant isoform expressed in the vasculature (4). Intracellular ET-1 is produced from inactive big ET-l via specific cleavage by endothelin converting enzyme-la that is expressed in endothelin producing cells (including endocardium and myocardium) and extracellular big ET- 1 is cleaved by endothelin converting enzyme- $1 \mathrm{~b}$ at the plasma membrane $(4,109)$. ET-1 generation is increased by many stimuli, including vasoactive hormones, growth factors, hypoxia, stress, lipoproteins, free radicals, endotoxin and cyclosporin (4). Production of ET-1 is inhibited by endothelium derived NO, nitrovasodilatators, natriuretic peptides, heparin and prostaglandins (4). Cultured endothelial cells secrete substantially more ET-1 toward the adjacent vascular smooth muscle than into the lumen, therefore endothelin is thought to be a locally acting paracrine substance rather than a circulating endocrine hormone (4).

Endothelins play an important role in cardiac and vascular pathology associated with heart failure (109). Plasma concentrations of endothelin-1 (ET-1) are increased two to three hold in patients with heart failure irrespective to aetiology (109). Plasma endothelin levels increase significantly (more than fivehold) in few hours after uncomplicated myocardial infarction in humans (46, 91). Increased levels of ET-1 in patients with heart failure correlate with patient outcomes and plasma endothelin concentrations correlate directly with pulmonary artery pressure and pulmonary vascular resistance (58). Increased production and biological activity of the potent vasoconstrictor and pro-inflammatory peptide endothelin is a hallmark of endothelial dysfunction (9), while the endothelial dysfunction is associated with accelerated progression of heart failure (30). Significant amounts of tissue ET-1 is found also in active coronary aterosclerotic plaques (107). ET-1 immunostaining localizes predominantly to areas with extensive macrophage infiltration and hypercellular regions with evidence for neovascularization - that suggests a role of local inflammatory processes in the 
production of ET-1 within aterosclerotic lessions (107). Endothelin is a potent vasoconstrictor, has inotropic and chemotactic properties, and has mitogenic effects on smooth muscle cells and fibroblasts, and it stimulates synthesis of inflammatory mediators in macrophages and fibronectin in smooth muscle cells $(32,46,56,58)$. Endothelin has other important effects in the heart, including stimulation of myocyte hypertrophy and atrial natriuretic peptide secretion from myocytes (61, $87)$. The overall action of endothelin is to increase blood pressure and vascular tone (4).

Biological activities of ET-1 are mediated mainly through two distinct receptor subtypes - $\mathrm{ET}_{\mathrm{A}}$ and $\mathrm{ET}_{\mathrm{B}}$ and they both are expressed in human atrial and myocardial myocytes, atrioventricular conducting system, endocardial cells, coronary and pulmonary arteries $(26,60,61,109)$. $\mathrm{ET}_{\mathrm{A}}$-receptors are located in vascular smooth muscle, but not in endothelial cells (4). $\mathrm{ET}_{\mathrm{B}}$ - receptors are located on endothelial cells (4). $\mathrm{ET}_{\mathrm{A}}$-receptor stimulation by ET-1 cause vascular smooth muscle constriction, but $\mathrm{ET}_{\mathrm{B}}$ - receptor activation by ET- 1 leads to vasodilation via production of NO and prostaglandins (4). Some $\mathrm{ET}_{\mathrm{B}}-$ receptors are located in vascular smooth muscle where thay may mediate vasoconstriction (14). Systemic administration of ET-1 leads to shortlived decrease (up to few minutes) in vascular resistance, followed by the longterm ( $\geq 1$ hour) increase and secondary, probably through increased afterload, decrease cardiac output $(4,46)$. The initial increase in perfusion is caused via nitric oxid and prostacyclin release by $\mathrm{ET}_{\mathrm{B}}$ stimulated endothelial cells (46). The decrease in perfusion is primarly mediated by $\mathrm{ET}_{\mathrm{A}}$ on smooth muscle cells. Activation of ET receptors lead to an induction of markers of cardiac remodeling, including mRNA for troponin I, myosin light chain 2 and skeletal alpha actin (87).

Endothelin receptor antagonists were developed for the treatment of patients with heart failure, but the effect in clinical heart failure trials has not been beneficial and has led to worsening outcomes in some setting $(58,96)$. Endothelin receptor antagonists have been shown to be beneficial in the setting of pulmonary hypertension and are currently approved for the treatment of pulmonary artery hypertension in patients with moderate disability (58).

\section{Vascular Endothelial Growth Factor}

Vascular endothelial growth factor (VEGF) is basic, heparin-binding, hemodinamic glycoprotein and is also known as a vascular permeability factor $(29,28)$. It is produced by a variety of adult tissues and vascular and inflammatory cells (25). VEGF in both physiologic and pathologic conditions induces endothelial cell migration, proliferation, and sprouting and results in angiogenesis and it is essential for embryonic vascular dvelopment (25). The location of the VEGF gene is in the chromosome 6p21.3 (102). VEGF proteins become available to endothelial cells by at least two different mechanisms: as freely diffusable proteins and following protease activation and cleavage of the longer isoforms
(28). There are three VEGF related factors - placental growth factor (PGF), vascular endothelial growth factor B (VEGF-B), Vascular endothelial growth factor C (VEGF-C). PGF can potentiate the bioactivity of low contentrations of VEGF on endothelial cell growth and it has minimal mitogenic activity on endothelial cells (71). PGF promotes cardiac hypertrophy $(3,25)$. VEGF-C is found in several human tissues including adult heart, it stimulates the growth of human lung endothelial cells and induces lymphangiogenesis (25, 29, 53). VEGF-B distributes primarily in the sceletal muscle and myocardium, and is coexpressed with VEGF (70). VEGF-B stimulates the growth of human vascular endothelial cells and may participate in the regulation of angiogenesis, particularly in muscle $(29,70)$. Lack of VEGF-B leads to characteristic defect (increase in the PQ interval in the ECG) in the atrial conduction system in mice and may yield to reduced functional recovery after myocardial ischemia $(1,7)$.

Biological activities of VEGF are mediated mainly through two receptors: VEGFR-1 (flt-1) and VEGFR-2 (flk-1). VEGFR-1 is expressed in a variety of cells including endothelial cells, smooth muscle cells, monocytes and macrophages, and hematopoietic stem cells (25). It may regulate arteriogenesis, pathological angiogenesis, myelomonocyte cell recruitment and lipid metabolism $(25,86)$. VEGFR-2 is mainly expressed on vascular endotheliel cells. In adults VEGFR-2 expression presents only at sites of active angiogenesis such as wound healing, tumors, and after myocardial inferction $(25,86)$. In myocardial infarction and sepsis VEGFR-2 is a major regulator of vascular permeability and cardiac dysfunction $(25,86)$. VEGFR-2 stimulates not only angiogenic signals, but also the secretion of various proteins such as the von Willebrand factor from endothelial cells (86).

VEGF are major molecules controlling vascular growth and function, vascular homeostasis, permeability, and vasodilatation (47). It is a potent mitogen for micro and macrovascular endohelial cells from arteriae, veins, and lyphatics, but it lacks significant mitogenic activity for other cell types $(29,28)$. VEGF is preventing apoptosis in vascular endothelial cells by inducing expression of the antiapoptotic proteins Bcl-2 and Al (35).

Myocardial neovascularization is important not only for heart development, but also during hypertrophy, ischemia and after myocardial infarction (98). VEGF mRNA expression in heart is induced by ischemia and cyclic stretch of cardiac myocytes and cardiac microvascular endothelial cells $(28,108)$. VEGF is critical for angiogenesis in the healing area after myocardial infarction - it is promptly expressed in the living cardiomyocytes around the infarcted loci and in the early stage also in infarcted cardiomyocytes $(25,44)$. Angiogenesis in the lesion begins at 4-5 hours and continues up to 90 days (25). VEGF has a role of enhancing the development of small coronary arteries that supply the ischemic myocardium, as well as a protective role against myocardial ischemia reperfusion injury (44). VEGF has been shown to be 
important for neovascularization of the chronically ischemic adult heart, it can stimulate collateral vessel development in the ischemic myocardium $(47,72)$.

There is also evidence of VEGF role in rheumatic and degenerative heart valve diseases. In contrast to healthy avascular aortic valves, stenotic valves show marked neovascularization - small microvessels, medium microvessels and organized arterioles (93). Neovascularization in the thickened aortic valves can suppress disease progression by providing oxygen and nutrients to deeper parts of hypertrophied valve leaflet, but on the other hand, provoke disease by facilitating the transport of inflammatory cells and lipids into the leaflets, neovascularization can accelerate valvular thickening and calcification (93). Calcification of rheumatic cardiac valve tissue and non-rheumatic degenerative valve tissue is similar to skeletal bone formation and is associated with neoangiogenesis which is stimulated by an active inflammatory process and the release of VEGF $(79,80)$. VEGF and it's receptors VEGFR-1 and VEGFR-2 are locally expressed in aortic valves and upregulated in stenotic valves $(93,17)$. VEGF and its receptors in stenotic valves are seen preferentially in endothelial cells and also to some extent in stromal myofibroblasts and histiocytic cells $(89,93)$. Must cell derived tumor necrosis factor $\alpha$, hypoxic conditions and tobacco smoke induces significant increase in VEGF secretion by cultured aortic valve myofibroblasts (93).

\section{CONCLUSIONS}

Cardiomyocyte apoptosis is an essential process in the pathogenesis and progression of heart failure irrespective to aetiology, but it can be reduced by appropriate timing of surgical intervention and precise choice of pre and postoperative medication. ANUP, ChgA, VEGF and ET- 1 secretion is a protective response to heart failure accordingly it allows to evaluate the preoperative condition, effectiveness of treatment and further prognosis as well as it may be a therapeutic target.

\section{Conflict of interest: None}

\section{REFERENCES}

1. Aase K, VonEuler G, Li X et al. Vascular Endothelial Growth Factor-B-Deficient Mice Display an Atrial Conduction Defect // Circulation, 2001; 104: 358.364

2. Abbote A, Biondi-Zoccai GGL, Bussani R. et al. Increased myocardial apoptosis in patients with unfavorable left ventricular remodeling and early symptomatic post-infarction heart failure // J Am Coll Cardiol, 2003; 41 (5): 753.-760

3. Accornero F, VanBerlo JH, Benard MJ. Placental growth factor regulates cardiac adaptation and hypertrophy through a paracrine mechanism // Circ Res, 2011 ; 109(3): 272.-280

4. Agapitov AV, Haynes WG. Role of endothelin in cardiovascular disease // J Renin Angiotensin Aldosterone Syst, 2002; 3 (1): 1-15
5. Ahmed A, Johansson O, Folan-Curran J. Distribution of PGP 9.5, TH, NPY, SP and CGRP immunoreactive nerves in the rat and guinea pig atrioventricular valves and chordae // J Anat, 1997; 191: 547.-560

6. Baba HA, Takeda A, Takeda N et al. Left Ventricular Assist Device: Morphological, Molecular and Genetic Changes After Mechanical Support // Ostadal B., Nagano M., Dhalla N.S. Genes and Cardiovascular Function / London: Springer, $2011 ; 235-240$

7. Bellamo D, Headrick JP, Silins GU et al. Mice lacking the vascular endothelial growth factor-B gene (Vegfb) have smaller hearts, dysfunctional coronary vasculature, and impaired recovery from cardiac ischemia //Circ Res, 2000; 86: 29.-35

8. Bhavani SS, Parshuram JS, Nitish RM et al. Chromogranin A: a novel susceptibility gene for essential hypertension // Cell Mol Life Sci, 2010; 67: 861-874

9. Böhm F, Pernow J. The importance of endothelin-1 for vascular dysfunction in cardiovascular disease // Cardiovasc Res, 2007; 76: 8-18

10. Bold AJ, Borenstein HB, Veress AJ et al. A rapid and potent natriuretic response to intravenous injection of atrial myocardial extract in rats // J Am Soc Nephrol, 2001; 13: 403.-409

11. Brooks ES, Rodeheffer RJ, Reeder GS et al. Expression of atrial natriuretic factor in the human ventricle is independent of chamber dilation // J Am Coll Cardiol, 1990; 16(7): 1589.-1593

12. Burninston JG, Saini A, Tan L et al. Aldosterone induces myocyte apoptosis in the heart and skeletal muscles of rats in vivo // J Mol Cell Cardiol, 2005; 39(2): 395.-399

13. Bussani R, Abbate A, Biondi-Zoccai GGL et al. Right ventricular dilatation after left ventricular acute myocardial infarction is predictive of extremely high peri-infarctual apoptosis at postmortem examination in humans // J Clin Pathol, 2003; 56: 672.-676

14. Canty JM. Coronary Blood Flow and Myocardial Ischemia // Bonow RO, Mann DL, Zipes DP. Braunwald's Heart Disease: A Textbook of Cardiovascular Medicine/ 9th ed.- Philadelphia: Elsevier Saunders, 2012; 1049.-1075

15. Cea LB. Natriuretic peptide family: new aspects // Curr Med Chem Cardiovasc Hematol Agents, 2005; 3(2): 87.-98

16. Ceconi C, Ferrari R, Bachetti T. et al. Chromogranin A in heart failure. A novel neurohumoral factor and a predictor for mortality // Eur Heart J, 2002; 23: 967-974

17. Chalajour F, Treede H, Gehling UM et al Identification and characterization of cells with high angiogenic potential and transitional phenotype in calcific aortic valve // Exp Cell Res, 2007; 313: 2326.-2335

18. Chen $\mathrm{P}$, Chen L, Cao J et al. Sympathetic nerve sprouting, electrical remodeling and the 
mechanisms of sudden cardiac death // Cardiovasc Res, 2001; 50: 409.-416

19. Chenn H.H., Burnett J.C. C-type natriuretic peptide: the endothelial component of the natriuretic peptide system // J Cardiovasc Pharmaco, 1998; 32(3): 22.-28

20. Chow LTC, Chow SSM, Anderson R.H et al. Autonomic Innervation of the Human Cardiac Conduction System: Changes from Infancy to Senility An Immunohistochemicaland Histochemical Analysis // Anat Rec, 2001; 264: 169-182

21. Chow LT, Chow SS, Anderson RH et al. The innervation of the human myocardium at birth // J Anat, 1995; 187: 107.-114

22. Chow LT, Chow SS, Anderson RH et al. The innervation of the human cardiac conduction system at birth // Brit Heart J, 1993; 69: 430.-435

23. Crick SJ, Wharton J, Sheppard $M N$ et al. Innervation of the human cardiac conduction system. A quantitative immunohistochemical and histochemical study // Circulation, 1994; 89: 1697.-1708

24. Crippa L, Bianci M, Colombo B et al. A new chromogranin A- dependent angiogenic switch activated by trombin // Blood, 2013; 121 (2): 392. -402

25. Dashkevich A, Lemstrom KB, Nykanem AI. VEGF Receptor Signaling in the Cardiac Lymphatic System // Karunamuni G. The Cardiac Lymphatic System. -New York: Springer, 2013- 125.-144

26. Davenport AP, Oreilly G, Molenaar P. Human Endothelin Receptors Characterized Using Reverse- Transcriptase-Polymerase Chain Reaction, in Situ Hybridisation and Subtype Selective Ligands BQ123 and BQ3020: Evidence for Expression of Etb Receptors in Human Vascular Smooth Muscle // J Cardiovasc Pharmacol, 1993; 22(8): 22.-25

27. Empel VPM., Bertrand ATA., Hofstra L et al. Myocyte apoptosis in heart failure // Cardiovasc Res, 2005; 67: $21-29$

28. Ferrera N. Molecular and viological properties of vascular endothelial growth factor // J Mol Med, 1999; 77: 527.-543

29. Ferrera N., Davis-Smyth T. The biology of vascular endothelial growth factor // Endocrine Reviews, 1997; 18(1): 4.-25

30. Fischer D, Rossa S, Landmesser U et al. Endothelial dysfunction in patients with chronic heart failure is independently associated with increased incidence of hospitalization, cardiac transplantation, or death // Eur Heart J, 2005; 26 (1): 65-69

31. Forssmann WG, Richter R, Meyer $M$. The endocrine heart and natriuretic peptides: histochemistry, cell biology, and functional aspects of the renal urodilation system // Histochem Cell Biol, 1998; 110:335.-357

32. Fujitami Y, Ninomiya H, Okada T et al. Supression of Endothelin-1-induced Mitogenic Responses of Human Aortic Smooth Muscle Cells by Interleukin-1 $\beta$ // J Clin Invest, 1995; 95: 2474.2482

33. Gavrieli Y, Sherman Y, Ben-Sasson SA Identification of programmed cell death in situ via specific labeling of nuclear DNA fragmentation // J Cell Bio, 1992; 119(3): 493.-501

34. Genest J, Libby P. Lipoprotein Disorders in Cardiovascular Disease // Bonow RO, Mann DL, Zipes DP. Braunwald`s Heart Disease: A Textbook of Cardiovascular Medicine/ 9th ed.- Philadelphia: Elsevier Saunders, 2012; 975.-995

35. Gerber HP, Dixit V, Ferrera N. Vascular endothelial growth factor induces expression of the antiapoptotic proteins $\mathrm{Bcl}-2$ and $\mathrm{Al}$ in vascular endothelial cells // J Biol Chem, 1998; 273 (21): 13313.-13316

36. Glattard E, Angelone T, Strub JM, et al. Characterization of natural vasostatin-containing peptides in rat heart // The FEBS Journal, 2006; 273: 3311-3321

37. Goetze JP, Alehagen U, Flyvbjerg A et al. Making sense of chromogranin A in heart disease // Lancet Diabetes Endocrinol, 2013; 1 (1): 7-8

38. Goetze JP, Hilsted LM, Rehfeldand JF et al. Plasma chromogranin A is a marker of death in elderly patients presenting with symptoms of heart failure // Endocr Connect, 2014; 3: 47-56

39. Gottieb RA, Burleson KO, Kloner RA et al. Reperfusion injury induces apoptosis in rabbit cardiomyocytes // J Clin Invest, 1994; 94: 1621.1628

40. Hasan W. Autonomic cardiac innervation. Development and adult plasticity //Organogenesis, 2013; 9(3): 176.-193

41. Heatwole LC. TUNEL Assay for Apoptotic Cells // Javois L.C. Methods in Molecular Biology: Immunocytochemical Methods and Protocols -2nd ed.- New Jersey: Humana Press, 1999; 141.148

42. Hengartner MO, Horvitz HR. Programmed cell death in Caenorhabditis elegans // Curr Opin Genetics Dev, 1994; 4: 581-586

43. Horl WH. Natriuretic peptides in acute and chronic kidney disease and during renal replacement therapy // J Investig Med, 2005; 53(7): 366.-370.

44. Ishikawa $\mathrm{Y}$, Akasaka $\mathrm{Y}$, Ishii $\mathrm{T}$ et al. Sequential changes in localisation of repair-related proteins (heat shock protein 70, ubiquitin and vascular endothelial growth factor) in the different changes of myocardial infarction // Histopathology, 2000; 37: $546 .-554$

45. Kabara M, Tatsumi T, Kambayashi D et al. Effects of ACE inhibition on myocardial apoptosis in an ischemia-reperfusion rat heart model // J Cardiovasc Pharmacol, 2003; 41: 880.-889

46. Kadzerski RM, Yanagisawa M. Endothelin system: The double edged sword in health and disease // Annu Rev Pharmacol Toxicol, 2001; 41: 851.-876 
47. Karu I, Starkopf J, Zilmer K et al. Growth Factors Serum Levels in Coronary Artery Disease Patients Scheduled for Bypass Surgery: Perioperative Dynamics and Comparisons with Healthy Volunteers // http://dx.doi. org/10.1155/2013/985404 (10.06.2014)

48. Kawai K, Quin F, Shite J et al. Importance of antioxidant and antiapoptotic effects of $\beta$-receptor blockers in heart failure therapy // Am J Physiol Heart Circ Physiol, 2004; 287(3): 1003.-1012

49. Kerr JFR, Willie AH, Currie AR. Apoptosis: a basic biological phenomenon with wide-ranging implications in tissue kinetics // Br J Cancer, 1972; 26: 239.-257

50. Krown KA, Page MT, Nguyen C et al. Tumor necrosis factor alpha-induced apoptosis in cardiac myocytes. Involvement of the sphingolipid signaling cascade in cardiac cell death // J Clin Invest, 1996; 98(12): 2854.-2865

51. Kuhn M. Endothelial actions of atrial and B-type natriuretic peptides // Br J Pharmacol, 2012; 166 (2): 522-531

52. Laslop A, Doblinger D, Weiss U. Proteolytic Processing of Chromogranins // Helle B., Aunis D. Chromogranins. Functional and Clinical Aspects. USA: Kluwer Academic Publishers, 2002; 155. 165

53. Lee J, Gray A, Yuan J et al. Vascular endothelial growth factor-related protein: a ligand and specific activator of the tyrosine kinase receptor Flt4 // Cell Biol, 1996; 93: 1988.-1992

54. Leri A, Claudio PP, Li Q. et al. Stretch-mediated release of angiotensin II induces myocyte apoptosis by activating p53 that enhances the local reninangiotensin system and decreases the Bcl-2-toBax protein ratio in the cell // J Clin Invest, 1998; 101(7): 1326.-1342

55. Loh YP, Cheng Y, Mahata SK et al. Chromogranin A and Derived Peptides in Health and Disease // J Mol Neurosc, 2012; 48: 347.-356

56. MacNulty EE, Plevin R, Wakelam MJO. Stimulation of the hydrolysis of phosphatidylinositol 4,5-bisphosphate and phosphatidylcholine by endothelin, a complete mitogen for Rat-1 fibroblasts // Biochem J, 1990; 272: 761.-766

57. Maisel A, Krishnaswamy P, Nowak RM et al. Rapid measurement of B-Type natriuretic peptide in the emergency diagnosis of heart failure // N Engl J Med, 2002; 347 (3): 161-167

58. Mann D. Pathophysiology of Heart Failure // Bonow RO, Mann DL, Zipes DP. Braunwald`s Heart Disease: A Textbook of Cardiovascular Medicine/ 9th ed.- Philadelphia: Elsevier Saunders, 2012.Pp. 487.-503

59. Marron K, Wharton J, Sheppard MN et al. Distribution, Morphology, and Neurochemistry of Endocardial and Epicardial Nerve Terminal Arborizations in the Human Heart // Circulation, 1995; 92: 2343.-2351
60. Molenaar P, Kuc RE, Davenport AP Characterisation of two new $\mathrm{ET}_{\mathrm{B}}$ selective radioligands, $\left[{ }^{125} \mathrm{I}\right]-\mathrm{BQ} 3020$ and $\left[{ }^{125} \mathrm{I}\right]-\left[\mathrm{Ala}^{1,3,11,15}\right]$ ET-1 in human heart // Brit J Pharmac, 1992; 107: 637.-639

61. Molenaar P, Oreilly G, Sharkey A. Characterisation and Localisation of Endotheli Receptor Subtypes in the Human Atrioventricular conducting System and Myocardium // Circ Res, 1993; 72(3): 526.538

62. Mukoyama M, Nakao K, Hosada K et al. Brain natriuretic peptide as a novel cardiac hormone in humans. Evidence for an exquisite dual natriuretic peptide system, atrial natriuretic peptide and brain natriuretic peptide // J Clin Inves, 1991; 87: 1402.1412

63. Nakagawa O, Ogawa $\mathrm{Y}$, Itoh $\mathrm{H}$ et al. Rapid Transcriptional Activation and Early mRNA Turnover of Brain Natriuretic Peptide in Cardiocyte Hypertrophy // J Clin Inves, 1995; 96: 1280-1287

64. Narula J, Haider N, Virmani R et al. Apoptosis in myocytes in end-stage heart failure // N Engl J Med, 1996; 335(16): 1182.-1189

65. Nichols $M$, Townsend $N$, Scarborough $P$ et al. Cardiovascular disease in Europe 2014: epidemiological update // Eur Heart J, 2014; 35 2950.-2959

66. Nobels FRE, Kwekkeboom DJ, Bouillon R et al. Review. Chromogranin A: it's clinical value as marker of neuroendocrine tumors // Eur J Clin Inves, 1998; 28: $431 .-440$

67. Noireaund J, Andiantsitohaina R. Recent Insights in the Paracrine Modulation of Cardiomyocyte Contractility by Cardiac Endothelial Cells // BioMed Research International, BioMed Research International, vol. 2014, Article ID 923805, 10 pages, 2014. doi:10.1155/2014/923805

68. Ogawa Y, Nakao K, Nakagawa O et al. Human C-type natriuretic peptide. Characterization of the gene and peptide //Hypertension, 1992; 19(6): 809.-813

69. Olivetti G, Quaini F, Lagrasta C et al. Acute myocardial infarction in humans is associated with activation of programmed myocyte cell death in the surviving portion of the heart // J Mol Cell Cardiol, 1996; 28(9): 2005.-2016

70. Olofsson B, Pajusala K, Kaipainen A et al. Vascular endothelial growth factor B, a novel growth factor for endothelial cells //Cell Biology, 1996; 93: 2576.-2581

71. Park EJ, Chen HH, Winer J et al. Placenta growth factor. Potentiation of vascular endothelial growth factor bioactivity, in vitro and in vivo, and high affinity binding to Flt- 1 but not to Flk-1/KDR // J Biol Chem, 1994; 269(41): 25646.-25654

72. Pearlman JD, Hibberd MG, Chuang ML et al. Magnetic resonance mapping demonstrates benefits of VEGF-induced myocardial angiogenesis // Nature Medicine, 1995; 1(10): 1085-1089 
73. Pieroni M, Corti A, Tota B et al. Myocardial production of chromogranin A in human heart: a new regulatory peptide of cardiac function // Eur Heart J, 2007; 28: 1117- 1127

74. Pilmane M, Ozoliņa L, Ābola Z et al. Growth Factors, Their Receptors, Neuropeptide-Containing Innervation, and Matrix Metalloproteinases in the Proximal and Distal Ends of the Esophagus in Children With esophageal Atresia // Medicina, $2011 ; 47(8): 453-460$

75. Plumpton C, Champeney R, Ashby MJ et al. Characteriszation of Endothelin Isoforms in Human Heart: Endothelin-2 Demonstrated // J Cardiovasc Pharmac, 1993; 22(8): 26.-28

76. Pucci A, Wharton J, Arbustini E et al. Localization of brain and atrial natriuretic peptide in human and porcine heart // Int J Cardiol, 1992; 34: 237.247

77. Rabkin SW. Review Article. Apoptosis in Human Acute Myocardial Infarction: The Rationale for Clinical Trials of Apoptosis Inhibition in Acute Myocardial Infarction // Scholarly Research Exchange, Volume 2009, Article ID 979318, http:// dx.doi.org/10.3814/2009/979318 (10.06.2015)

78. Rabkin SW, Kong JY. Nitroprusside induces cardiomyocyte death: interaction with hydrogen peroxide // Am J Physiol Heart Circ Physiol, 2000; 279(6): 3089.-3100

79. Rajamannan NM, Nealis T., Subramainiam M. Calcified rheumatic valve neoangiogenesis is associated with vascular endothelial growth factor expression and osteoblast-like bone formation // Circulation, 2005; $111(24)$ : 3296.-3301

80. Rajamannan NM, Subramainiam M, Rickard D et al. Human aortic valve calcification is associated with an osteoblast phenotype //Circulation, 2003; 107(17): 2181.-2184

81. Rechardt L, Aalto-Setala K, Purjeranta $M$ et al. Peptidergic innervation of human arial myocardium: an electron microscopical and immunocytochemical study // J Auton Nerv Syst, 1986; 17: 21.-32

82. Røsjø H, Masson S, Latini R et al. Prognostic value of chromogranin A in chronic heart failure: data from the GISSI-Heart Failure trial // Eur J Heart Fail, 2010; 12: 549-556

83. Saraste A, Pulkki K, Kallajoni M et al. Apoptosis in Human Acute Myocardial Infarction // Circulation, 1997; 95: 320.-323

84. Schaper J, Lorenz-Meyer S, Suzuki K The Role of Apoptosis in Dilated Cardiomyopathy // Herz, 1999; 24(3): 219.-224

85. Schirger JA, Heublein DM, Chen HH et al. Presence of Dendroaspis natriuretic peptidelike immunoreactivity in human plasma and its increase during human heart failure // Mayo Clinic Proceedings, 1999; 74(2): 126.-130

86. Shibuya M. Vascular Endothelial Growth Factor (VEGF) and Its Receptor (VEGFR) Signaling in Angiogenesis // Genes and Cancer, 2011; 12(2): 1097.- 1105
87. Shubeita HE, McDonough PM, Harris AN et al. Endothelin induction of inositol phospholipid hydrolysis, sarcomere assembly, and cardiac gene expression in ventricular myocytes. A paracrine mechanism for myocardial cell hypertrophy // J Biol Chem, 1990; 265 (33): 20555.-20562

88. Sinagra G, Bussani R, Abbate A et al. Left Ventricular Diastolic Filling Pattern at Doppler Echocardiography and Apoptotic Rate in Fatal Acute Myocardial Infarction // Am J Cardiol, 2007; 99(3):307.-309

89. Soni Y, Salo T, Satta J. Angiogenesis is involved in the pathogenesis of nonrheumatic aortic valve stenosis // Human Pathology, 2003; 34(8): 756.763

90. Statistical data on population mortality // http:// WwW.spkc.gov.lv/veselibas-aprupes-statistika/ (14.06.2015)

91. Stewart DJ, Kubac G, Costello KB. Increased plasma endothelin-1 in the early hours of acute myocardial infarction // J Am Coll Cardiol, 1991; 18(1): 38.-43

92. Suzuki Y, Suzuki H, Ohtake R et al. Changes in the plasma and urine alpha human atrial natriuretic peptide (alpha hANP) concentration in patients with thyroid disorders // Endocrinologia Japonica, 1988; 35(6): 907.-913

93. Syvaranta S, Helske S, Laine M. et al. Vascular endothelial growth factor-secreting mast cells and myofibroblasts: a novel self-perpetuating angiogenic pathway in aortic valve stenosis // Arterioscler Thromb Vasc Biol, 2010; 30(6): 1220.1227

94. Takemura G, Fujiwara H, Mukoyama M. et al. Expression and distribution of atrial natriuretic peptide in human hypertrophic ventricle of hypertensive hearts and hearts with hypertrophic cardiomyopathy // Circulation, 1991; 83(1): 181.190

95. Takemura G, Takatsu Y, Doyama K. et al. Expression of Atrial and Brain Natriuretic Peptides and their Genes in Hearts of Patients with Cardiac Amyloidosis // J Am Coll Cardiol, 1998; 31: 254.265

96. Teerlink JR. Recent Heart Failure Trials of Neurohormonal Modulation (OVERTURE and ENABLE): Approaching the Asymtote of Efficacy? // J Card Fail, 2002; 8(3): 124

97. Thompson RJ, Doran JF, Jackson P. Et al. PGP 9.5- a new marker for vertebrate neurons and neuroendocrine cells // Brain Research, 1983; 278: $224 .-228$

98. Tomanek RJ, Zheng W, Yue X. Growth factor activation in myocardial vascularization: Therapeutic implications // Mol Cell Biol, 2004; 264: 3.- 11

99. Tota B, Cerra CM, Gattuso. Review. Catheholamines, cardiac natriuretic peptides and chromogranin A: evolution and physiopathology of whip- brake system of the endocrine heart // J Exp Biol, 2010; 213: 3081.-3103 
100. Uusimaa P, Ruskoaho H, Vuolteenaho O. et al. Plasma vasoactive peptides after acute myocardial infarction in relation to left ventricular dysfunction // Int J Cardiol, 1999; 69: 5.-14

101. Veinot JP, Gattinger DA, Fliss H. Early apoptosis in human myocardial infarcts // Hum Path, 1997; 28(4): 485.-492

102. Vincenti V, Cassano C, Rocchi M et al. Assignment of the vascular endothelial growth factor gene to human chromosome 6p21.3 // Circulation, 1996; 93: 1493.-1495

103. Vracko R, Thorning D, Frederickson RG. Nerve Fibers in Human Myocardial Scars // Hum Path, 1998; 22: 138.-146.

104. Weiergraber M, Pereverzev A, Vajna R, Henry M. et al. Immunodetection of alphalE voltage-gated $\mathrm{Ca}(2+)$ channel in chromogranin-positive muscle cells of rat heart, and in distal tubules of human kidney // J Histochem Cytochem, 2000; 48 (6): 807.-819

105. Wharton J, Polak J, Gordon L. et al. Immunohistochemical Demonstration of Human Cardiac Innervation Before and After Transplantation // Circ Res, 1990; 66(4): 900.-912.
106. Yanagisawa M, Kurihora H, Kimura S. et al. A novel potent vasoconstrictor peptide produced by vascular endothelial cells //Nature, 1988; 332:411.-415

107. Zeiher AM, Goebel H, Schachinger V et al. Tissue endothelin-1 immunoreactivity in the active coronary atherosclerotic plaque. A clue to the mechanism of increased vasoreactivity of the culprit lesion in unstable angina // Circulation, 1995; 91: 941.-947

108. Zheng W, Seftor E, Meininger CJ. et al. Mechanisms of coronary angiogenesis in response to stretch: role of VEGF and TGF-beta // Am J Physiol Heart Circ Physiol, 2001; 280: 909.-917

109. Zolk O, Böhm M. The role of the cardiac endothelin system in heart failure // Nephrol Dial Transplant, 2000; 15 (6): 758-760

\section{Address:}

Edite Kulmane

Pauls Stradins Clinical University Hospital

Department of Cardiac Surgery

Pilsonu str. 13

LV-1002, Riga, Latvia

e-mail: ekulmane@gmail.com 